\title{
Modeling the Interaction Between Cumulus Convection and Linear Gravity Waves Using a Limited-Domain Cloud System-Resolving Model
}

\section{Citation}

Kuang, Zhiming M. 2008. Modeling the interaction between cumulus convection and linear waves using a limited domain cloud system resolving model. Journal of the Atmospheric Sciences 65, no. 2: 576-591.

\section{Published Version}

http://dx.doi.org/10.1175/2007JAS2399.1

\section{Permanent link}

http://nrs.harvard.edu/urn-3:HUL.InstRepos:3203013

\section{Terms of Use}

This article was downloaded from Harvard University's DASH repository, and is made available under the terms and conditions applicable to Other Posted Material, as set forth at http:// nrs.harvard.edu/urn-3:HUL.InstRepos:dash.current.terms-of-use\#LAA

\section{Share Your Story}

The Harvard community has made this article openly available.

Please share how this access benefits you. Submit a story.

\section{Accessibility}




\section{Modeling the interaction between cumulus convection and linear gravity waves using a limited domain cloud system resolving model}

Zhiming Kuang

Department of Earth and Planetary Sciences and School of Engineering and Applied Sciences, Harvard University

Submitted to the Journal of the Atmospheric Sciences on January 9, 2007, Revised, June 12, 2007

Corresponding author address:

Zhiming Kuang

Department of Earth and Planetary Sciences and School of Engineering and Applied Sciences, Harvard University, 20 Oxford St. Cambridge, MA 02138

(Tel) 617 495-2354 $\quad$ (Fax) 617-495-7660

Email: kuang@fas.harvard.edu 


\begin{abstract}
A limited domain cloud system-resolving model (CSRM) is used to simulate the interaction between cumulus convection and 2-dimensional linear gravity waves, a single horizontal wavenumber at a time. With a single horizontal wavenumber, soundings obtained from horizontal averages of the CSRM domain allow us to evolve the largescale wave equation and thereby model its interaction with cumulus convection. It is shown that convectively coupled waves with phase speeds of $8-13 \mathrm{~m} / \mathrm{s}$ can develop spontaneously in such simulations. The wave development is weaker at long wavelengths $(>\sim 10000 \mathrm{~km})$. Waves at short wavelengths $(\sim 2000 \mathrm{~km})$ also appear weaker, but the evidence is less clear because of stronger influences from random perturbations. The simulated wave structures are found to change systematically with horizontal wavelength, and at horizontal wavelengths of $2000-3000 \mathrm{~km}$ they exhibit many of the basic features of the observed 2-day waves. The simulated convectively coupled waves develop without feedbacks from radiative processes, surface fluxes, or wave radiation into the stratosphere, but vanish when moisture advection by the large-scale waves is disabled. A similar degree of vertical tilt is found in the simulated convective heating at all wavelengths considered, consistent with observational results. Implications of these results to conceptual models of convectively coupled waves are discussed. Besides being a useful tool for studying wave-convection interaction, the present approach also represents a useful framework for testing the ability of coarse-resolution CSRMs and Single Column Models in simulating convectively coupled waves.
\end{abstract}




\section{Introduction}

How cumulus convection interacts with large-scale circulations is a long-standing problem in meteorology and remains not well understood. One class of such interaction, namely that of convectively coupled waves, has attracted much attention (e.g. Lindzen, 1974; Emanuel, 1987; Neelin et al., 1987; Wang, 1988; Takayabu, 1994; Wheeler and Kiladis, 1999; Mapes, 2000; Majda and Shefter, 2001; Sobel and Bretherton, 2003; Haertel and Kiladis, 2004; Fuchs and Raymond, 2005; Khouider and Majda, 2006). Besides being quite well observed, their apparent linear characteristics suggest that they may serve as a good starting point for more general investigations of the interaction between cumulus convection and the large-scale circulation.

Various numerical experiments using cloud system resolving models (CSRM) have been used to simulate these waves (e.g. Grabowski and Moncrieff, 2001; Kuang et al., 2005; Tomita et al., 2005; Tulich et al., 2006). In these studies, large domain sizes (thousands of kilometers or more) are used to accommodate the large-scale waves. In this paper, we model this interaction in a limited domain CSRM. Inspired by the observed linear characteristics of these waves, we study each individual horizontal wavenumbers separately. This methodology is explained in more detail in section 2 . Section 3 contains a description of the model that we use and the experimental setup. The simulation results are described in section 4. Additional implications to conceptual models of convectively coupled waves are discussed in Section 5, followed by the conclusions (section 6). 


\section{Methodology}

Let us start by considering the 2-dimensional (2D) anelastic linearized perturbation equations of momentum, continuity, and hydrostatic balance. In the following, all equations are for the large-scale wave:

$$
\begin{gathered}
\bar{\rho} u_{t}^{\prime}=-p_{x}^{\prime}-\varepsilon \bar{\rho} u^{\prime} \\
\left(\bar{\rho} u^{\prime}\right)_{x}+\left(\bar{\rho} w^{\prime}\right)_{z}=0 \\
p_{z}^{\prime}=\bar{\rho} g \frac{T^{\prime}}{\bar{T}}
\end{gathered}
$$

where $\varepsilon$ is the mechanical damping coefficient and all other symbols assume their usual meteorological meaning. The background mean variables are denoted with an overbar. We treat a single horizontal wavenumber $\mathrm{k}$ at a time, and thus assume solutions of the form

$$
\left[u^{\prime}, w^{\prime}, T^{\prime}, p^{\prime}\right](x, z, t)=\operatorname{real}([\hat{u}, \hat{w}, \hat{T}, \hat{p}](z, t) \exp (-i k x))
$$

The lower boundary condition is $\mathrm{w}^{\prime}=0$ and the radiation upper boundary condition is (see e.g. Durran (1999), Section 8.3.2):

$$
\hat{p}=\bar{\rho} \hat{w} N /|k|
$$

where $\mathrm{N}$ is the buoyancy frequency at the upper boundary and $N^{2}=\frac{g}{\bar{T}}\left(\frac{d \bar{T}}{d z}+\frac{g}{c_{p}}\right)$.

Eliminating u' and p' from Eqs. (1)-(3) and applying Eq. (4), we have

$$
\left[\left(\frac{\partial}{\partial t}+\varepsilon\right)(\bar{\rho} \hat{w})_{z}\right]_{z}=-k^{2} \frac{\bar{\rho} g}{\bar{T}} \hat{T}
$$

For a given $\mathrm{x}=\mathrm{x}_{0}$, multiply Eq. (6) by $\exp \left(-\mathrm{ikx} \mathrm{x}_{0}\right)$ and take the real component, we have: 


$$
\left[\left(\frac{\partial}{\partial t}+\varepsilon\right)\left(\bar{\rho} w^{\prime}\left(x_{0}, z, t\right)\right)_{z}\right]_{z}=-k^{2} \frac{\bar{\rho} g}{\bar{T}} T^{\prime}\left(x_{0}, z, t\right)
$$

We now use the CSRM domain to represent a vertical line at $\mathrm{x}=\mathrm{x}_{0}$. When only a single horizontal wavenumber is present, T' along this vertical line, computed as the deviation of the CSRM domain-averaged temperature profile from a reference profile ${ }^{1}$, can be used with Eq. (7) and the boundary conditions to evolve w' of the large-scale wave along this vertical line. Effects of this vertical velocity are then included in the CSRM integration as source terms of temperature and moisture, applied uniformly in the horizontal. Integration of the CSRM produces new domain averaged profiles of temperature and moisture, the equations of which may be written as:

$$
\begin{gathered}
T_{t}^{\prime}+w^{\prime}\left(\frac{d \bar{T}}{d z}+\frac{g}{c_{p}}\right)=S_{T}^{\prime} \\
q_{t}^{\prime}+w^{\prime} \frac{d \bar{q}}{d z}=S_{q}^{\prime}
\end{gathered}
$$

where all variables are at $\mathrm{x}=\mathrm{x}_{0}$, and $\mathrm{S}_{\mathrm{T}}$ and $\mathrm{S}_{\mathrm{q}}$ are the perturbation temperature and moisture tendencies due to cumulus convection simulated explicitly by the CSRM. The new (virtual) temperature profile is then used again in Eq. (7) to update w' for the next time step, completing the interaction between wave and convection. As the sign of the wavenumber does not enter in the calculation, the results can be viewed as representing a vertical line in eastward or westward propagating waves or in standing waves (excluding the nodal points).

The present approach may be viewed as the cloud-resolving cumulus parameterization (CRCP) approach (Grabowski, 2001) with the large-scale dynamics reduced to that of a

\footnotetext{
${ }^{1}$ In the actual integration, virtual temperature is used.
} 
single linear wave. It is also similar in spirit to recent suggestions of using a limited domain CSRM or a single column model with parameterized large-scale dynamics to study the sensitivity of convection to various forcing (Sobel and Bretherton, 2000; Bergman and Sardeshmukh, 2004; Mapes, 2004; Raymond and Zeng, 2005). Indeed, Eq. (6) is the same as $\partial / \partial z$ of Eq. (A3) of Bergman and Sardeshmukh, and the treatment of vertical advection in Eq. (8) and (9) is standard. The previous studies, however, were not formulated to model convectively coupled waves. While using a limited domain CSRM, as opposed to a large domain CSRM, does allow substantial savings in computation, the more important advantage of the present approach is the simplicity brought about by the simplified large-scale dynamics (linear waves of a single horizontal wavenumber). We do leave out aspects of the convection-wave coupling such as the nonlinear interactions between waves of different scales, but these aspects may be better addressed in future studies after the simpler problem of interaction between convection and linear waves is better understood.

\section{Model and Experimental Setup}

We have implemented the above procedure in the System for Atmospheric Modeling (SAM) version 6.4, which is a new version of the Colorado State University Large Eddy Simulation / Cloud Resolving Model (Khairoutdinov and Randall, 2003). Readers are referred to Khairoutdinov and Randall (2003) for details about the model. Briefly, the model uses the anelastic equations of motion and the prognostic thermodynamic variables are the liquid water static energy, total non-precipitating water and total precipitating water. The model uses bulk microphysics with five types of hydrometeors: cloud water, cloud ice, rain, snow, and graupel. For this study, we use a simple Smagorinsky-type 
scheme for the effect of subgrid-scale turbulence, and for simplicity, compute the surface fluxes using bulk aerodynamic formula with constant exchange coefficients and surface wind speed. The surface temperature is set to $29.5^{\circ} \mathrm{C}$.

To be more representative of the conditions over convective regions in the tropics, we prescribe the background vertical velocity profile (shown in Figure 1) to be that averaged over the Large Scale Array (LSA) during the intensive operating period (IOP) of the Tropical Ocean Global Atmosphere Coupled Ocean-Atmosphere Response Experiment (TOGA-COARE) (Webster and Lukas, 1992) from November 1, 1992 through February 28 1993, using the gridded product by Ciesielski et al. (2003). Background vertical shear is not included in this study.

For each of our simulations, we first run the model as a conventional CSRM, i.e. without coupling to gravity wave dynamics, for 30 days (referred to as the background integration). Coupling is then activated and the model is integrated for another 70 days. Unless otherwise noted, a 10-day mechanical damping timescale is used. This value is more appropriate for the free troposphere but is applied uniformly at all heights for simplicity. The radiative tendency profile is prescribed and constant in time throughout the simulations. This profile and the initial temperature and moisture profiles are the statistical equilibrium profiles from an earlier long integration of the model as a conventional (uncoupled) CSRM with interactive radiation. The radiation schemes used are those of the National Center for Atmospheric Research (NCAR) Community Climate Model (CCM3) (Kiehl et al., 1998). For simplicity, we have removed the diurnal cycle as in our previous studies (Kuang and Bretherton, 2004). 
We have verified that in the background integration, after the first few days, there is little drift in temperature and moisture over all heights in the troposphere, and we use averages over the last 10 days to define the background temperature and moisture profiles, and thus the background virtual temperature profile. This is used as the reference profile for computing the perturbation (virtual) temperature in Eq. (3) after coupling to gravity wave dynamics is activated. After this coupling is activated, for simplicity, the background vertical velocity acts only on the background vertical temperature and moisture profiles and represents a constant forcing of the CSRM.

The horizontal resolution is $2 \mathrm{~km}$ and there are 64 points in the vertical with the vertical grid size varying from $75 \mathrm{~m}$ near the surface to $500 \mathrm{~m}$ in the middle and upper troposphere and to about $1 \mathrm{~km}$ near the domain top (at $32 \mathrm{~km}$ ). A wave-absorbing layer is placed over the upper third of the domain. Note that this layer only affects waves explicitly simulated by the CSRM. The upper boundary condition for the large-scale wave is Eq. (5). Unless otherwise noted, the domain has 192 by 192 grid points in the horizontal. The SAM integration uses a variable time step determined by its Courant-Friedrichs-Lewy (CFL) number and the integration of the large-scale gravity wave equation uses a time step of 1 minute. The domain averages are sampled every time step and output every 3 hours. Because of the finite domain size of the CSRM, viewing it as a vertical line in the largescale wave field is an idealization and assumes that the horizontal scale of the wave is much larger than the CSRM domain size. Thus, we shall only apply this method to waves with wavelengths of thousands of kilometers or more. 


\section{Results}

Fig. 2 shows the time series of the domain-averaged precipitation of a set of experiments with horizontal wavenumbers (in unit of $2 \pi / 1000 \mathrm{~km}$ ) of $0.5,0.35,0.2,0.15,0.1,0.075$ and 0.05 (or wavelengths of $2000 \mathrm{~km}, 2857 \mathrm{~km}, 5000 \mathrm{~km}, 6667 \mathrm{~km}, 10000 \mathrm{~km}, 13333 \mathrm{~km}$ and $20000 \mathrm{~km}$ ). Before coupling to wave dynamics is activated, the CSRM produces a domain averaged precipitation with a mean value of $9.1 \mathrm{~mm} /$ day and a standard deviation of $0.6 \mathrm{~mm} /$ day. After coupling is activated, pronounced oscillations develop spontaneously in all cases except at $20000 \mathrm{~km}$. As the wavelength increases beyond $10000 \mathrm{~km}$, it takes longer for the oscillation to grow to its equilibrated amplitude and the equilibrated amplitude also decreases. Since the $13333 \mathrm{~km}$ case does not appear to have reached its equilibrated amplitude in Fig.2, we have run it for another 50 days and its amplitude remains unchanged from that over the last 20 days shown in Fig.2.

There is also a tendency for the wave amplitude to decrease as wavelength decreases beyond $5000 \mathrm{~km}$. This is not as clear because oscillations at shorter wavelengths are less regular, owing to random perturbations by convection on the domain-averaged virtual temperature profiles. At shorter wavelengths, virtual temperature perturbations of a given size produce larger vertical velocity perturbations (Eq. (6)). This makes the shorter wavelength cases more susceptible to the effect of these random perturbations so the simulations are not as clean. The random virtual temperature perturbations are smaller with a larger domain. The horizontal domain size of 192 by 192 points was chosen largely as a balance between this consideration and the computational cost. With smaller domains, the oscillation becomes stronger and more irregular at short wavelengths 
(Fig.3ab), although at wavelengths of 5000km and longer, effects from such random perturbations are small, and the results are not sensitive to domain size (Fig.3cd).

Amplitudes achieved by the mid/long wavelength waves are affected by the mechanical damping timescale. Representative results with a mechanical damping time of 4 days and with no mechanical damping are shown in Figs. 4 and 5, respectively. Stronger damping reduces the amplitude that medium/long wavelength waves, particularly the long wavelength waves, can achieve. With no mechanical damping or sufficiently weak damping and strong wave growth, the waves equilibrate at amplitudes approximately equal to that of the basic state convection (the $20000 \mathrm{~km}$, no damping case eventually reaches this amplitude as well) and the positive (stronger precipitation) phase can achieve greater amplitude than the negative (weaker precipitation) phase. The bound on the negative phase is presumably due to the fact that precipitation cannot be negative. The bound on the positive phase must also result from nonlinearity intrinsic to convection because the large-scale waves here are strictly linear. We defer the discussion of nonlinearity to a later study but note that while it cannot address the full nonlinear interaction between wave and convection because of the assumption of linear wave dynamics, the present methodology can still be a useful simplifying framework for studying nonlinearity intrinsic to convection and its role in wave-convection coupling.

For all damping values, the wave growth at long wavelengths is slower. This is true in simulations without mechanical damping as well, even though in this case the equilibrated wave amplitudes at long wavelengths are as large as those at medium wavelengths (Fig. 5). Fig. 6 attempts to quantify this. We first do a running mean of the precipitation time series to remove the sub-daily variations. We then identify the local 
maxima that occur after coupling to wave dynamics is activated, and use linear interpolation to compute the wave amplitude for the positive phase at each time. The wave amplitude is taken to be 0 at the time when coupling to wave dynamics is activated. The solid line in Fig. 6 shows the time for the wave amplitude of the positive phase to grow to $3 \mathrm{~mm} /$ day (an arbitrary choice, but using other values does not change the conclusion). Repeating the calculation using the minima gives the dashed line in Fig. 6. These estimates are less reliable for the shorter wavelengths, so only the results for the longer wavelengths are shown. There is a clear tendency for smaller growth rates at longer wavelengths beyond a few thousands of kilometers. It is worth noting that a simple conceptual model of convectively coupled waves constructed and analyzed by Kuang (2007) produces this behavior of smaller growth rates at longer wavelengths, and the reason for this behavior in that model is the damping effect due to convection's tendency to remove moisture anomalies.

Fig. 7 shows the phase speeds of the simulated waves. The period is estimated as twice the lag time for which the autocorrelation of precipitation is most negative. Other ways such as dividing the elapsed time by the number of cycles in between produce similar results. There is a tendency for the phase speeds to be slower at longer wavelengths and with weaker damping. Closer examination indicates that the wave periods tend to be longer when the waves are saturated (i.e. with amplitudes roughly equal to that of the basic state convection). How wavelength and nonlinearity intrinsic to convection might affect the wave speeds could be a topic worthy of further investigation.

Fig. 8-10 show the structures of the simulated oscillations at wavelengths of $2000 \mathrm{~km}$, $5000 \mathrm{~km}$, and $10000 \mathrm{~km}$, along with estimated phase speeds. The structures are 
constructed by regressing various fields onto precipitation anomalies with a range of lags. For a given wavelength, all fields are scaled by a factor so that the minimum in the composite precipitation is $-10 \mathrm{~mm} /$ day. This is done to facilitate comparison across different wavelengths. We only show the results with a 10-day mechanical damping time; the results for the 4-day damping and no damping cases are similar. Fig. 8 may be compared with the structure of 2-day waves (Haertel and Kiladis (2004), hereafter HK04, their Fig. 4), as the two have similar wave periods. The comparison shows good resemblance in their basic features. This includes: the near surface temperature is roughly in phase (out of phase) with lower tropospheric (upper tropospheric) temperature; cold anomalies tend to coincide with dry anomalies for the near surface air while the opposite relationship exist in the lower troposphere between $\sim 600 \mathrm{hPa}$ and $\sim 900 \mathrm{hPa}$; convective heating above the subcloud layer (the cloud base is located at $\sim 930 \mathrm{hPa}$ or $670 \mathrm{~m}$ ) has a tilted structure, with the anomalies progressing from the lower troposphere to the upper troposphere; at times of enhanced (reduced) convective heating in the lower troposphere, there is enhanced (reduced) convective cooling and drying in the subcloud layer. While the resemblance is quite good, there are some differences as well. For example, the simulated temperature/moisture anomalies above the subcloud layer are somewhat smaller than those observed for 2-day waves while those in the subcloud layer are larger (the convective heating anomalies are of similar magnitude). Also, peaks of the temperature anomalies in the lower troposphere are between 750 and $800 \mathrm{hPa}$ for the observed 2-day waves while those in the simulation are located somewhat higher at around $700 \mathrm{hPa}$. Many factors may contribute to such differences. First of all, our experiments are for 2D gravity waves. The 2-day waves defined in HK04 differ from 2D 
gravity waves in some potentially important ways: they are affected by planetary rotation and propagate westward only and their meridional scale of convection is narrower than that of their dynamical fields (see, e.g., Fig. 3 of HK04). Also, while we prescribe the mean vertical velocity based on TOGA-COARE, we do not include mean horizontal advection or use nudging to match the mean thermodynamic profiles to the observed one. Furthermore, while the resolution employed here is typical of today's CSRM simulations, they are too coarse to simulate shallow convection accurately (and are far from achieving numerical convergence). Aspects of the model, e.g. the microphysics, also may not be sufficiently accurate. It is not yet clear which factors are responsible for the differences between the results in Fig. 8 and those of the 2-day waves. While ultimately one would like the numerical models to simulate all aspects of the observed waves well, this is beyond the scope of the present study. The goal here is to capture the basic features in a simple setting. By this measure the simulated waves are sufficiently similar to the observed ones to lend us confidence that results here will be relevant to convectively coupled waves in the real atmosphere, notwithstanding the aforementioned caveats. We have tested the effect of various simplifications (used mostly for ease of interpretation) in our experimental design. For instance, when the CSRM is coupled to gravity wave dynamics, we have the background vertical velocity act on the background temperature and moisture profiles so that it represents a constant forcing on the CSRM. In the real atmosphere, the background vertical velocity would instead act on the actual vertical temperature and moisture profiles. We have also assumed a uniform mechanical damping timescale for simplicity, while in reality we expect stronger damping in the lower troposphere. We have performed simulations with the background vertical velocity 
advecting the actual vertical temperature and moisture profiles and with the damping timescale decreasing linearly from 10 days at $5 \mathrm{~km}$ (and above) to 1 day at $1 \mathrm{~km}$ (and below). Such changes affect the details of simulated wave patterns but not their basic features.

One may also compare the 5000km case (Fig. 9) with the observed Kelvin wave structure (Fig.5 of Straub and Kiladis, 2003). The comparison is not as clear-cut as in the 2-day wave and $2000 \mathrm{~km}$ wave case, where both waves have similar coherence, estimated here by how fast the envelope amplitude of the composite precipitation decreases with increasing lag (Fig. 2b of HK04 and Fig.8a of this paper). The coherence of the observed Kelvin waves, seen from Fig. 5a of Straub and Kiladis (2003), with outgoing longwave radiation in place of precipitation, is substantially lower than that of the simulated 5000km waves shown in Fig. 9a. This indicates that the observed Kelvin wave structures may include contributions from a range of wavelengths. Notwithstanding the above differences, the most basic patterns in the two figures are still in reasonable agreement.

Comparing Figs. 8-10 reveals systematic changes in the wave structure with wavelength. This is true at the other wavelengths as well (Fig. 11). While the q' patterns have a backward tilted structure in all cases, the anomaly in the mid-troposphere (between 400 and $600 \mathrm{hPa}$ ) increases substantially with wavelength relative to those in the lower troposphere (between 700 and $900 \mathrm{hPa}$ ). There is also a tendency for temperature anomalies in the lower troposphere to become more in phase with the subcloud layer moist static energy as the wavelength increases. Some indications of these changes can be seen in observations as well. Comparing the observed structures of Kelvin waves (Fig. 5 in Straub and Kiladis, 2003) and 2-day waves (Fig. 4 in HK04), the Kelvin waves have 
longer wavelengths and their temperature anomalies in the lower troposphere are more in phase with the subcloud layer moist static energy. Their moisture anomalies between 700 and $900 \mathrm{hPa}$ are also not as prominent as those of the 2-day waves. These changes may be related to the difference between the wave period and the internal convective timescales, and are interesting features that need to be explained by theories of waveconvection interaction. Amplitudes of the moisture and temperature anomalies also increase with wavelength, especially at longer wavelengths where the increase is about linear. This is expected as we have normalized the waves based on precipitation, which is roughly proportional to vertical velocity. Temperature/moisture variations per unit vertical velocity variation tend to increase with wavelength (or wave period), as seen in Eq. (8) and (9).

In a study of the 2-day waves, HK04 showed that the first two vertical modes based on a vertical mode decomposition, assuming a rigid lid at $150 \mathrm{hPa}$, can capture the basic features of the heating and temperature patterns. We have done a similar vertical decomposition with a rigid lid at $14 \mathrm{~km}$. In the literature, the method of Fulton and Schubert (1985) is typically used to solve for eigenmodes of the vertical structure equation

$$
\Omega_{z z}+\frac{k^{2}}{c_{j}^{2}} N^{2} \Omega=0
$$

where $\Omega$ is the vertical structure function for $\bar{\rho} w$ and $\mathrm{c}_{\mathrm{j}}$ are the phase speeds of the free vertical modes. We have used the Matlab solver for eigen-problems and found it to be adequate. Figs. 12 and 13 show the results for the wavelength of $5000 \mathrm{~km}$. Results for other wavelengths are similar. The first two vertical modes (with dry speeds of 49 and 
$23 \mathrm{~m} / \mathrm{s}$, respectively) capture the heating structure very well and the residues are small. The first two modes also capture the general patterns of the temperature anomalies in the bulk of the troposphere, but not the details; temperature anomalies of higher vertical modes are present. These results are similar to the findings of HK04 for the 2-day waves. While replacing the radiation upper boundary condition by a rigid lid is an approximation, simulations with a rigid lid at $14 \mathrm{~km}$ (to be described in section $5 \mathrm{a}$ ), for which the vertical mode decomposition is exact, give similar results. A major feature not captured by the first two vertical modes is temperature anomalies in and near the subcloud layer, which are distinct from anomalies above and peak near the surface. Moisture anomalies in and near the subcloud layer are also distinct from those above, and tend to peak just below the cloud base (located near 930hPa). These results support the notion (although by no means guarantee) that a model that consists of the first two vertical modes and the subcloud layer might be able to represent the basic dynamics of convectively coupled waves.

\section{Discussions}

\section{a. Instability mechanisms}

A number of mechanisms have been suggested as important for generating convectively coupled waves and in setting their phase speeds, such as the wind induced surface heat exchange or the WISHE mechanism (Emanuel, 1987; Neelin et al., 1987), wave radiation into the stratosphere (Lindzen, 1974; Lindzen, 2003), stratiform instability (Mapes, 2000), and moisture feedback (Khouider and Majda, 2006). The WISHE mechanism is absent in our simulations because we use a bulk aerodynamic formula with a constant 
wind speed. So are feedbacks from radiation as radiative tendencies are prescribed and constant in time. To evaluate the importance of wave radiation into the stratosphere, we replace the radiation upper boundary condition, Eq. (5), by a rigid lid condition $(w=0)$ at $14 \mathrm{~km}$. In this case, the development of convectively coupled waves (Fig. 14) and the basic wave patterns remain the same (Fig. 15 shows the results for the wavelength of $5000 \mathrm{~km}$; other wavelengths are similar). The main change is that with a rigid lid, largescale waves no longer propagate into the stratosphere. Temperature anomalies near the very top of Fig. 15 are above the rigid lid and are due solely to the convective heating there. In this simulation, we have also held the surface fluxes constant in time (at appropriate values) to completely eliminate feedbacks from surface fluxes (positive or negative). This has no effect on our conclusion about the role of wave radiation into the stratosphere, but reinforces the conclusion that surface flux feedbacks are not essential for the simulated waves.

We now remove vertical moisture advection by the large-scale waves by having wave vertical velocity acting only on temperature but not on moisture. This eliminates the convectively coupled waves as shown in Fig. 16 for wavelengths of 2000, 5000, and $10000 \mathrm{~km}$. The remaining variations in precipitation are presumably forced by random variations in convection. This demonstrates that vertical advection of moisture by largescale waves is essential to the existence of convectively coupled waves. The effect of moisture on convection must also be essential because convection is the way by which moisture can in turn affect the large-scale waves. While moisture also directly affects density, and hence the waves, through the virtual effect, this effect is small and secondary, as confirmed by experiments in which the virtual effect is neglected when 
integrating the large-scale wave equations. The importance of moisture-convection feedback was previously shown in the context of Madden-Julian Oscillation-like coherences (Grabowski and Moncrieff, 2004). Their simulations were done on a global domain using the CRCP approach and moisture variations were suppressed by nudging. The demonstration here is arguably cleaner as it avoids nudging. The essentialness of moisture effect demonstrated here is in contrast to the view expressed in Mapes' original simple tropical wave model (Mapes, 2000), which neglects the moisture effect. In more recent developments, free tropospheric moisture is included as an important component (Khouider and Majda, 2006; Kuang 2007), and an instability that arises from a feedback between wave, convection, and free tropospheric moisture is illustrated in Fig. 11 of Kuang (2007).

b. Parameterization of stratiform heating in models with two vertical modes

Many current stratiform instability models (Mapes, 2000; Majda and Shefter, 2001;

Khouider and Majda, 2006) parameterize stratiform heating through a lagged relationship to deep convective heating (typically with a fixed time lag of $3 \mathrm{hr}$ ). This follows the treatment of Mapes (2000) and is based on the life cycle of mesoscale convective systems (MCS). However, a fixed time lag implies that as wavelength increases, the phase lag between deep convective and stratiform heating, measured in radians, and hence the tilt in the heating structure, will become increasingly small. This is not consistent with the present simulations where a similar degree of tilt in the heating structure is seen at all wavelengths (Fig. 8-11). To quantify this, we shall take the first vertical mode (from the vertical decomposition described in section 4) as the deep convective heating and the second mode as the congestus (when it is positive) and stratiform heating (when 
negative). In other words, we are viewing the CSRM simulations in a two vertical model framework. Following earlier studies (e.g. Mapes, 2000; Khoudier and Majda, 2006), the word "stratiform" ("congestus") is used in this context to refer to a heating anomaly structure that is positive (negative) aloft and negative (positive) below, with the view that such a heating anomaly is associated with enhanced (reduced) stratiform and/or reduced (enhanced) congestus cloud populations, similar to that depicted in Fig.11 of Mapes et al. (2006). We then compute the lagged correlation between the strength of two heating modes, and the lag between deep convective and stratiform heating is defined as the lag with the most negative correlation. The results are shown in Fig 17 for the various wavelengths. It is clear that when the CSRM simulations are interpreted in a two vertical mode framework, stratiform heating does not lag convective heating by a fixed time. A better approximation instead is the lag increasing roughly linearly with wavelength (or wave period). The results remain the same for simulations with a rigid lid, in which case the vertical mode decomposition is exact. Similar conclusions were reached in observational studies (Kiladis et al., 2005; Mapes et al., 2006). Therefore, in large-scale convectively coupled waves, stratiform heating cannot be tied to deep convective heating with a fixed lag as in MCSs (and in many of the current stratiform instability models). Other factors must be modulating the strength of stratiform heating. Mid-tropospheric humidity appears a likely candidate. That mid-tropospheric humidity can affect tropical deep convection is well supported by observations, numerical simulations, and theoretical reasoning (Brown and Zhang, 1997; Sherwood, 1999; Parsons et al., 2000; Redelsperger et al., 2002; Ridout, 2002; Derbyshire et al., 2004; Takemi et al., 2004; Roca et al., 2005; Kuang and Bretherton, 2006). All else being equal, a dry mid-troposphere is unfavorable 
to deep convection because lateral entrainment of drier environmental air by the rising air parcels leads to more evaporative cooling, and hence negative buoyancy. We hypothesize that from the perspective of large-scale wave-cumulus interaction, the mid-tropospheric humidity is the main control on the depth of convection: when the mid-troposphere is moist, cumulus ensembles can reach higher, and thus have a larger stratiform heating component; when the mid-troposphere is dry, cumulus ensembles are limited to lower altitudes, and thus have a larger congestus heating component. This is consistent with the results shown in Fig. 8-11, and appears to be an attractive way for determining stratiform/congestus heating in conceptual models.

c. Quasi-equilibrium

An important way to conceptualize the interaction between large-scale circulation and cumulus convection is the concept of quasi-equilibrium (QE) (Arakawa and Schubert, 1974), which states that convection should maintain a state of statistical equilibrium with the large-scale flow. In some previous simple models of wave-convection interaction (Emanuel et al., 1994), the approximate invariance of convectively available potential energy (CAPE) is used as a simplification for QE over the whole depth of the troposphere. Such models of wave-convection interaction do not yield instability without WISHE or other destabilization mechanisms, and therefore do not explain the development of convectively coupled waves in our simulations. The model by Mapes (2000) does not utilize the QE concept, and instead emphasizes triggering and inhibition. We agree that triggering and inhibition are important aspects of cumulus dynamics. However, they reflect more of a view on individual storm scale, and on the large scale, conceptual simplification may still be achieved through a quasi-equilibrium view. The 
composite wave structures in Figs. 8-11 suggest a plausible simplification of QE. They show that temperature in the lower troposphere (instead of the entire free troposphere as in Emanuel et al. (1994)) is more or less in phase with the boundary layer moist static energy, especially at long wavelengths. This is seen in the observational study by Sobel et al. (2004) as well. It therefore appears that near invariance of a shallow CAPE, defined as the integrated buoyancy for undiluted parcels only up to the mid-troposphere, may be a more suitable simplification to QE than the deep CAPE traditionally used. The problem with using the near invariance of the deep CAPE is that the effect of lateral entrainment is neglected. As discussed in the previous subsection, lateral entrainment is a very important aspect that makes the height of convection sensitive to tropospheric moisture. By using a shallow CAPE, we by no means imply that cloud parcels do not experience entrainment in the lower troposphere. However, the cumulative effect of entrainment is smaller in the lower troposphere because of the shorter distance traveled by the cloud parcels and their smaller moist static energy difference from the environment. Therefore, it may be a reasonable simplification to neglect the effect of lateral entrainment over the lower half of the troposphere, and only include it further up through the control of mid-tropospheric humidity on the depth of convection. These ideas will be discussed in more detail in Kuang (2007) that describes a simple model of the convectively coupled waves.

\section{Concluding remarks}

In this paper, we demonstrate that a limited domain CSRM coupled with linear wave dynamics can be used to simulate wave-cumulus interaction. With this approach, convection is simulated in three-dimensions at a relatively high resolution without 
overwhelmingly high computational cost, and the large-scale dynamics is simplified to that of linear gravity wave of a single horizontal wavenumber. This reduces the problem to a very simple setting for studying wave-cumulus interaction.

Convectively coupled waves with phase speeds of $8-13 \mathrm{~m} / \mathrm{s}$ can develop spontaneously in these simulations. The wave development is weaker at long wavelengths $(>\sim 10000 \mathrm{~km})$. Waves at short wavelengths ( $2000 \mathrm{~km})$ also appear weaker although the evidence is less clear because the short wavelengths are more susceptible to the effect of random perturbations from the CSRM simulations. The simulated wave structures at horizontal wavelengths of 2000-3000km resemble those of the observed 2-day waves in their basic features. The simulated wave structures are found to change systematically with the horizontal wavelength, an interesting behavior that needs an explanation from theories of wave-cumulus interaction. The separate integration of large-scale dynamics and the CSRM (in the same way as in the CRCP approach) enables us, for example, to turn off moisture advection by the large-scale waves and replace the upper boundary condition for the large-scale waves in a straightforward manner. Our results indicate that convectively coupled waves can develop without feedbacks from radiative processes, surface fluxes, or wave radiation into the stratosphere, but vanish when moisture advection by the largescale waves is disabled. The tilt in the convective heating pattern is found to remain roughly the same at all wavelengths considered. This challenges the treatment in many current models (Mapes, 2000; Majda and Shefter, 2001; Khouider and Majda, 2006), where stratiform heating is treated as lagging deep convective heating by a fixed time lag, and indicates that other factors must be controlling the strength of stratiform heating. We suggest mid-tropospheric humidity as a likely candidate. The simulations also show that, 
similar to observations, temperature in the lower troposphere is roughly in phase with the boundary layer moist static energy. This suggests that some simplified treatment of QE might be used to gain conceptual simplification of the wave-convection interaction. A conceptually simple model of convectively coupled waves has been constructed based on these considerations (Kuang 2007). The simulation results here have been further used to constrain the parameters of that model.

While the present approach includes only one horizontal wavenumber a time, it includes all vertical wavenumbers and is suitable for studying how the observed vertical structures are selected. We have focused on results for one background mean state, namely that with the mean vertical velocity of TOGA-COARE, but have experimented with other background mean states (for example, without the mean vertical velocity or with additional moisture advection). In these cases, convectively coupled waves can also develop spontaneously but the strength of the instability varies substantially with the background mean states. Documenting and understanding how the waves and the instability change with the mean state is a problem of considerable interest and is currently being investigated. Because of its simplicity, the present approach is also a useful framework for testing the performance of Single Column Models with parameterized cumulus dynamics and coarse-resolution CSRMs in simulating convectively coupled waves. Such tests are currently being conducted and the results will be reported in future publications. 


\section{Acknowledgements}

The author thanks Marat Khairoutdinov for making the SAM model available, Dave Raymond, Adam Sobel, Stefan Tulich, and an anonymous reviewer for their constructive reviews, and Chris Walker for helpful comments. The author also wishes to acknowledge Dr. Scott Fulton's generosity for making his vertical transform code available, even though the code was not used in this study. This work was supported partly by the Modeling, Analysis and Prediction (MAP) Program in the NASA Earth Science Division. 


\section{References:}

Arakawa, A. and W. H. Schubert, 1974: Interaction of a Cumulus Cloud Ensemble with Large-Scale Environment.1. Journal of the Atmospheric Sciences, 31, 674-701.

Bergman, J. W. and P. D. Sardeshmukh, 2004: Dynamic stabilization of atmospheric single column models. Journal Of Climate, 17, 1004-1021.

Brown, R. G. and C. D. Zhang, 1997: Variability of midtropospheric moisture and its effect on cloud-top height distribution during TOGA COARE. Journal of the Atmospheric Sciences, 54, 2760-2774.

Ciesielski, P. E., R. H. Johnson, P. T. Haertel, and J. H. Wang, 2003: Corrected TOGA COARE sounding humidity data: Impact on diagnosed properties of convection and climate over the warm pool. Journal Of Climate, 16, 2370-2384.

Derbyshire, S. H., I. Beau, P. Bechtold, J. Y. Grandpeix, J. M. Piriou, J. L. Redelsperger, and P. M. M. Soares, 2004: Sensitivity of moist convection to environmental humidity. Quarterly Journal Of The Royal Meteorological Society, 130, 30553079.

Durran, D. R., 1999: Numerical Methods for Wave Equations in Geophysical Fluid Dynamics. Springer-Verlag.

Emanuel, K. A., 1987: An Air-Sea Interaction-Model Of Intraseasonal Oscillations In The Tropics. Journal Of The Atmospheric Sciences, 44, 2324-2340.

Emanuel, K. A., J. D. Neelin, and C. S. Bretherton, 1994: On Large-Scale Circulations in Convecting Atmospheres. Quarterly Journal of the Royal Meteorological Society, 120, 1111-1143. 
Fuchs, Z. and D. J. Raymond, 2005: Large-scale modes in a rotating atmosphere with radiative-convective instability and WISHE. Journal Of The Atmospheric Sciences, 62, 4084-4094.

Fulton, S. R. and W. H. Schubert, 1985: Vertical Normal Mode Transforms - Theory And Application. Monthly Weather Review, 113, 647-658.

Grabowski, W. W., 2001: Coupling cloud processes with the large-scale dynamics using the Cloud-Resolving Convection Parameterization (CRCP). Journal of the Atmospheric Sciences, 58, 978-997.

Grabowski, W. W. and M. W. Moncrieff, 2001: Large-scale organization of tropical convection in two-dimensional explicit numerical simulations. Quarterly Journal of the Royal Meteorological Society, 127, 445-468.

—_ 2004: Moisture-convection feedback in the tropics. Quarterly Journal Of The Royal Meteorological Society, 130, 3081-3104.

Haertel, P. T. and G. N. Kiladis, 2004: Dynamics of 2-day equatorial waves. Journal of the Atmospheric Sciences, 61, 2707-2721.

Khairoutdinov, M. F. and D. A. Randall, 2003: Cloud resolving modeling of the ARM summer 1997 IOP: Model formulation, results, uncertainties, and sensitivities. Journal of the Atmospheric Sciences, 60, 607-625.

Khouider, B. and A. J. Majda, 2006: A simple multicloud parameterization for convectively coupled tropical waves. Part I: Linear analysis. Journal of the Atmospheric Sciences, 63, 1308-3123. 
Kiehl, J. T., J. J. Hack, G. B. Bonan, B. A. Boville, D. L. Williamson, and P. J. Rasch, 1998: The National Center for Atmospheric Research Community Climate Model: CCM3. Journal of Climate, 11, 1131-1149.

Kiladis, G. N., K. H. Straub, P. T. Haertel, 2005: Zonal and vertical structure of the Madden-Julian Oscillation, Journal of the Atmospheric Sciences, 62, 2790-2809.

Kuang, Z. M., 2007: A moisture-stratiform instability for convectively coupled waves, Journal of the Atmospheric Sciences, submitted.

Kuang, Z. M. and C. S. Bretherton, 2004: Convective influence on the heat balance of the tropical tropopause layer: A cloud-resolving model study. Journal of the Atmospheric Sciences, 61, 2919-2927.

Kuang, Z. M. and C. Bretherton, 2006: A mass flux scheme view of a high-resolution simulation of a transition from shallow to deep cumulus convection. Journal of the Atmospheric Sciences, 63, 1895-1909.

Kuang, Z. M., P. N. Blossey, and C. S. Bretherton, 2005: A new approach for 3D cloudresolving simulations of large-scale atmospheric circulation. Geophysical Research Letters, 32.

Lindzen, R. S., 1974: Wave-CISK in the tropics. Journal of the Atmospheric Sciences, 32, 156-179.

— 2003: The interaction of waves and convection in the tropics. Journal of the Atmospheric Sciences, 60, 3009-3020.

Majda, A. J. and M. G. Shefter, 2001: Models for stratiform instability and convectively coupled waves. Journal of the Atmospheric Sciences, 58, 1567-1584. 
Mapes, B. E., 2000: Convective inhibition, subgrid-scale triggering energy, and stratiform instability in a toy tropical wave model. Journal of the Atmospheric Sciences, 57, 1515-1535.

$\ldots$, 2004: Sensitivities of cumulus-ensemble rainfall in a cloud-resolving model with parameterized large-scale dynamics. Journal of the Atmospheric Sciences, 61, 2308-2317.

Mapes, B. E., S. Tulich, J.-L. Lin, and P. Zuidema, 2006: The mesoscale convection life cycle: building block or prototype for large-scale tropical waves? Dyn. Atmos. Oceans., 42, 3-29.

Neelin, J. D., I. M. Held, and K. H. Cook, 1987: Evaporation-Wind Feedback And LowFrequency Variability In The Tropical Atmosphere. Journal Of The Atmospheric Sciences, 44, 2341-2348.

Parsons, D. B., K. Yoneyama, and J. L. Redelsperger, 2000: The evolution of the tropical western Pacific atmosphere-ocean system following the arrival of a dry intrusion. Quarterly Journal Of The Royal Meteorological Society, 126, 517-548.

Raymond, D. J. and X. P. Zeng, 2005: Modelling tropical atmospheric convection in the context of the weak temperature gradient approximation. Quarterly Journal of The Royal Meteorological Society, 131, 1301-1320.

Redelsperger, J. L., D. B. Parsons, and F. Guichard, 2002: Recovery processes and factors limiting cloud-top height following the arrival of a dry intrusion observed during TOGA COARE. Journal Of The Atmospheric Sciences, 59, 2438-2457. 
Ridout, J. A., 2002: Sensitivity of tropical Pacific convection to dry layers at mid- to upper levels: Simulation and parameterization tests. Journal Of The Atmospheric Sciences, 59, 3362-3381.

Roca, R., J. P. Lafore, C. Piriou, and J. L. Redelsperger, 2005: Extratropical dry-air intrusions into the West African monsoon midtroposphere: An important factor for the convective activity over the Sahel. Journal Of The Atmospheric Sciences, 62, 390-407.

Sherwood, S. C., 1999: Convective precursors and predictability in the tropical western Pacific. Monthly Weather Review, 127, 2977-2991.

Sobel, A. H., and C. S. Bretherton, 2000: Modeling tropical precipitation in a single column. J. Climate, 13, 4378-4392.

Sobel, A. H., and C. S. Bretherton, 2003: Large-scale waves interacting with deep convection in idealized mesoscale model simulations, Tellus, 55A, 45-60.

Sobel, A. H., and S. E. Yuter, C. S. Bretherton, G. N. Kiladis: Large-scale meteorology and deep convection during TRMM KWAJEX, Monthly Weather Review, 132, $422-444$.

Straub and Kiladis, 2003: The observed structure of convectively coupled Kelvin waves: Comparison with simple models of coupled waves instability, Journal Of The Atmospheric Sciences, 60, 1655-1668.

Takayabu, Y. N., 1994: Large-Scale Cloud Disturbances Associated With Equatorial Waves.1. Spectral Features Of The Cloud Disturbances. Journal Of The Meteorological Society Of Japan, 72, 433-449. 
Takemi, T., O. Hirayama, and C. H. Liu, 2004: Factors responsible for the vertical development of tropical oceanic cumulus convection. Geophysical Research Letters, 31.

Tomita, H., H. Miura, S. Iga, T. Nasuno, and M. Satoh, 2005: A global cloud-resolving simulation: Preliminary results from an aqua planet experiment. Geophysical Research Letters, 32.

Tulich, S., D. Randall, and B. Mapes, 2007: Vertical-Mode and Cloud Decomposition of Large-Scale Convectively Coupled Gravity Waves in a Two-Dimensional CloudResolving Model. Journal of the Atmospheric Sciences.

Wang, B., 1988: Dynamics Of Tropical Low-Frequency Waves - An Analysis Of The Moist Kelvin Wave. Journal Of The Atmospheric Sciences, 45, 2051-2065.

Webster, P. J. and R. Lukas, 1992: Toga Coare - the Coupled Ocean Atmosphere Response Experiment. Bulletin of the American Meteorological Society, 73, 13771416.

Wheeler, M. and G. N. Kiladis, 1999: Convectively coupled equatorial waves: Analysis of clouds and temperature in the wavenumber-frequency domain. Journal of the Atmospheric Sciences, 56, 374-399. 


\section{Figures}

Figure 1 Prescribed large-scale vertical velocity in the simulations.

Figure 2 Domain averaged precipitation as a function of time after coupling to gravity wave is activated for wavelengths of (from top to bottom) $2000 \mathrm{~km}, 2857 \mathrm{~km}$, $5000 \mathrm{~km}, 6667 \mathrm{~km}, 10000 \mathrm{~km}, 13333 \mathrm{~km}$ and $20000 \mathrm{~km}$.

Figure 3 Domain averaged precipitation as a function of time for wavelengths of $2000 \mathrm{~km}$

( $\mathrm{a}$ and $\mathrm{b}$ ), and $5000 \mathrm{~km}$ (c and d). A horizontal domain of 192 by 192 grid points is used in (a) and (c) and a horizontal domain of 96 by 96 grid points is used in (b) and (d).

Figure 4 Same as Fig. 2 except for representative cases with a mechanical damping time of 4 days.

Figure 5 Same as Fig. 2 except for representative cases with no mechanical damping.

Figure 6 Time for the wave amplitude of the positive (dashed, circle) and negative (solid, diamond) phases to grow to $3 \mathrm{~mm} /$ day in the no mechanical damping cases

Figure 7 Estimated wave phase speeds at different wavelengths with a mechanical damping time of 4 days (diamonds), 10 days (circles), and with no mechanical damping (asterisks).

Figure 8 Composite wave structures for the wavelength of 2000km: (a) precipitation, (b) temperature, (c) specific humidity, (d) convective heating, (e) convective drying, and (f) vertical pressure velocity. Contour intervals are indicated above each plot. Negative contours are dashed and the zero contours are omitted. The estimated phase speed is shown in (a).

Figure 9 Same as Figure 8 but for the wavelength of $5000 \mathrm{~km}$. 
Figure 10 Same as Figure 8 but for the wavelength of 10000km.

Figure 11 Same as Figure 8 except for temperature (left) and specific humidity (right) at wavelengths of (from top to bottom), $2857 \mathrm{~km}, 6667 \mathrm{~km}$, and $13333 \mathrm{~km}$.

Figure 12 Temperature (left) and convective heating (right) structures reconstructed from the first two vertical modes.

Figure 13 Residues in temperature (left) and convective heating (right) from reconstructing with the first two vertical modes.

Figure 14 Same as Figure 2 except when a rigid lid condition is used at $14 \mathrm{~km}$ and for wavelengths of (from top to bottom) $2000 \mathrm{~km}, 5000 \mathrm{~km}$, and $10000 \mathrm{~km}$.

Figure 15 Same as Figure 9 except with a rigid lid at $14 \mathrm{~km}$ and constant surface heat fluxes.

Figure 16 Same as Figure 2 except with vertical advection of moisture by large-scale waves disabled and for wavelengths of (from top to bottom) $2000 \mathrm{~km}, 5000 \mathrm{~km}$, and $10000 \mathrm{~km}$.

Figure 17 The estimated lag between deep convective heating and stratiform heating as a function of wavelength. 


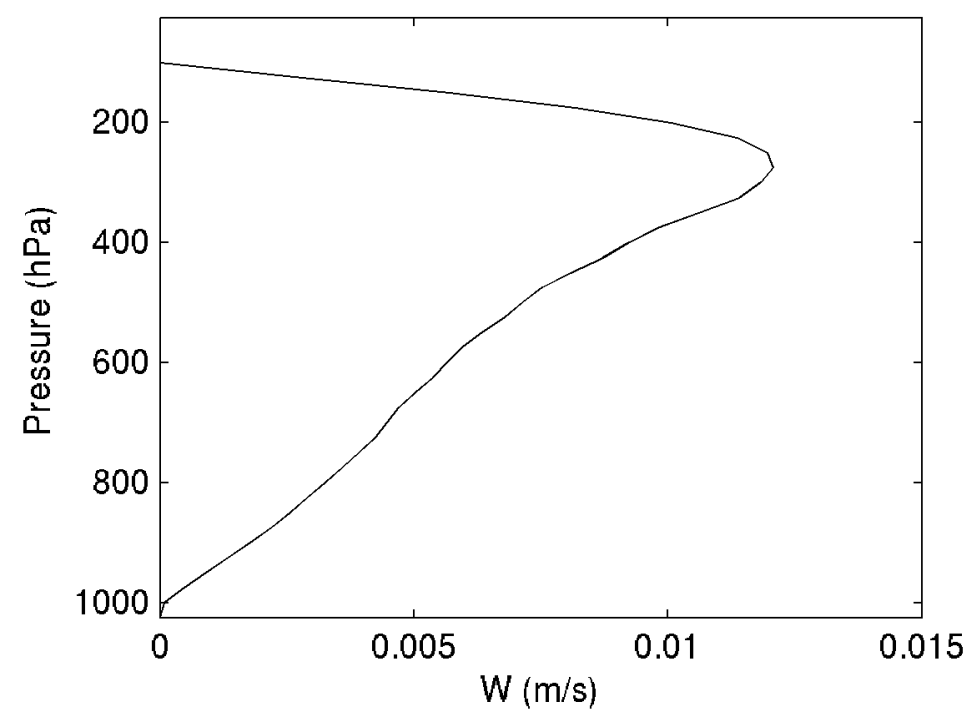

Figure 1 Prescribed large-scale vertical velocity in the simulations. 


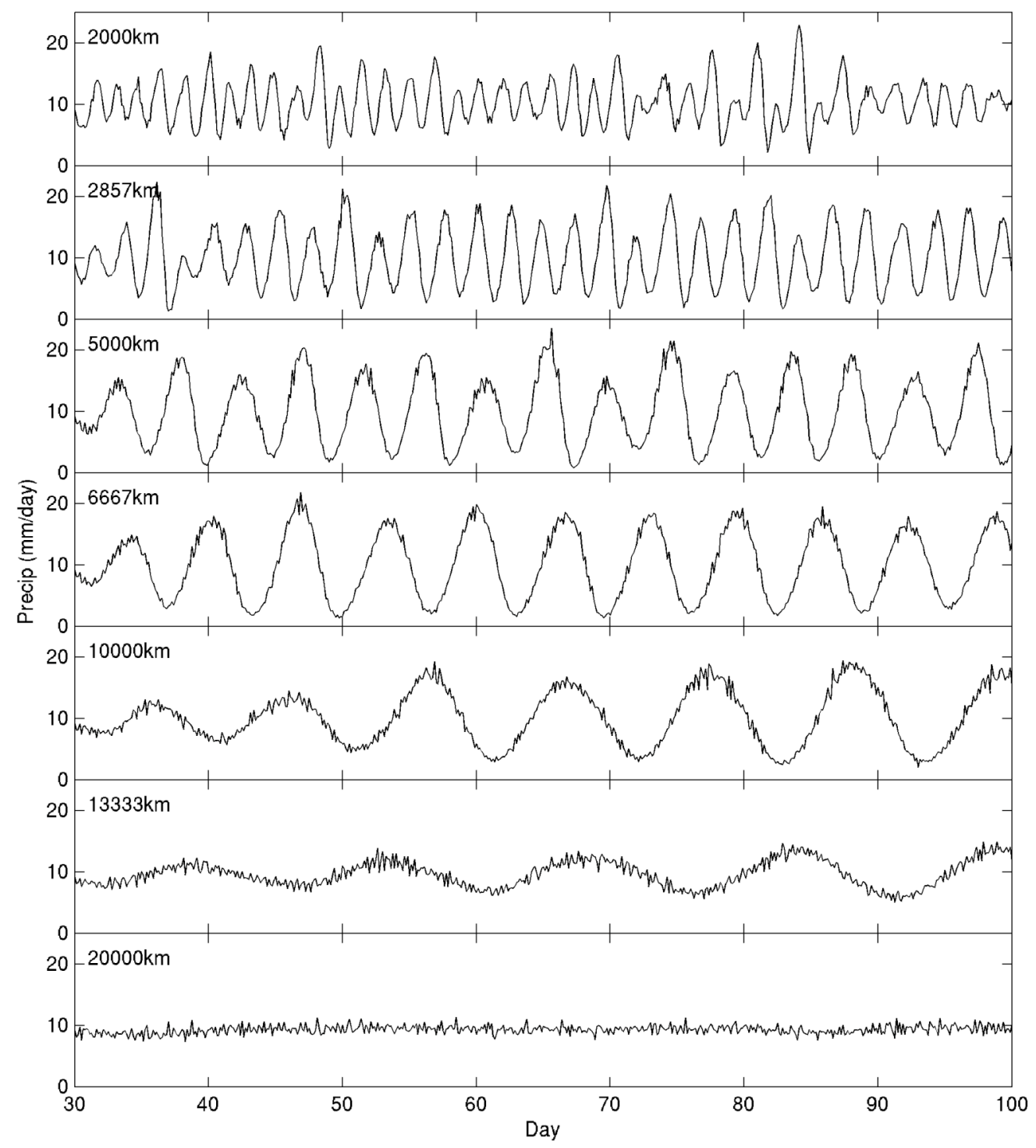

Figure 2 Domain averaged precipitation as a function of time after coupling to gravity wave is activated for wavelengths of (from top to bottom) $2000 \mathrm{~km}, 2857 \mathrm{~km}$, $5000 \mathrm{~km}, 6667 \mathrm{~km}, 10000 \mathrm{~km}, 13333 \mathrm{~km}$ and $20000 \mathrm{~km}$. 


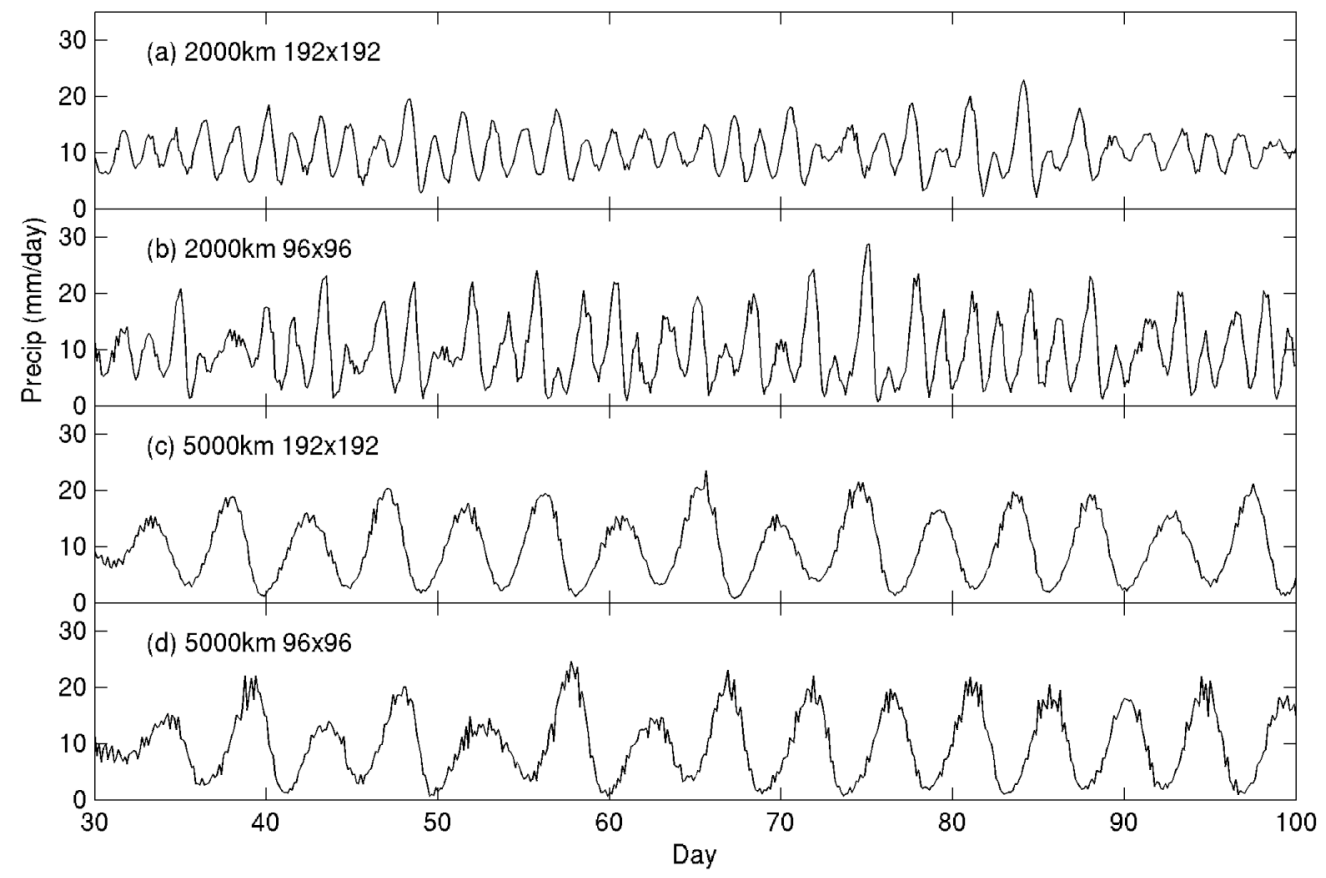

Figure 3 Domain averaged precipitation as a function of time for wavelengths of $2000 \mathrm{~km}$ (a and b), and 5000km (c and d). A horizontal domain of 192 by 192 grid points is used in (a) and (c) and a horizontal domain of 96 by 96 grid points is used in (b) and (d). 


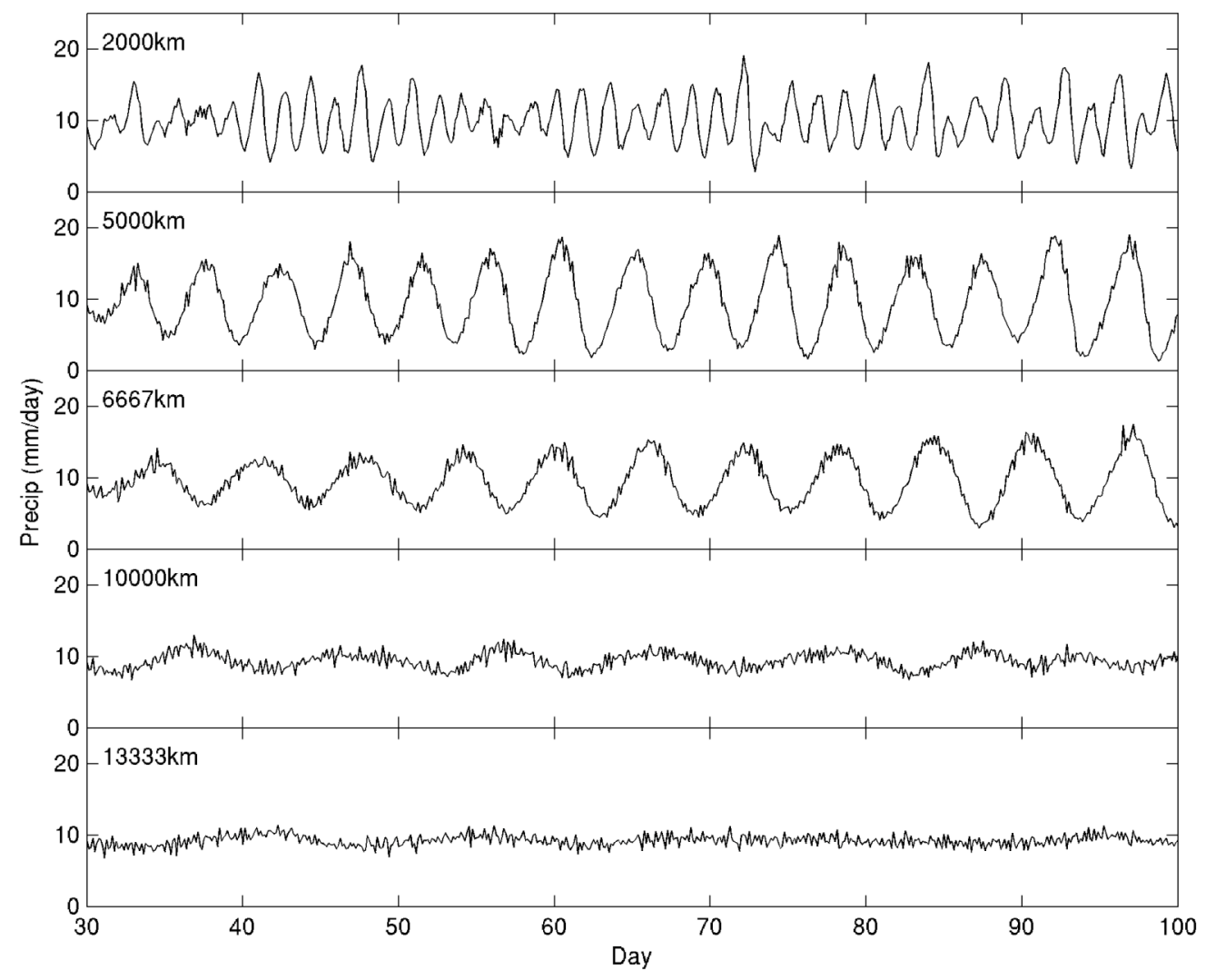

Figure 4 Same as Fig. 2 except for representative cases with a mechanical damping time of 4 days. 


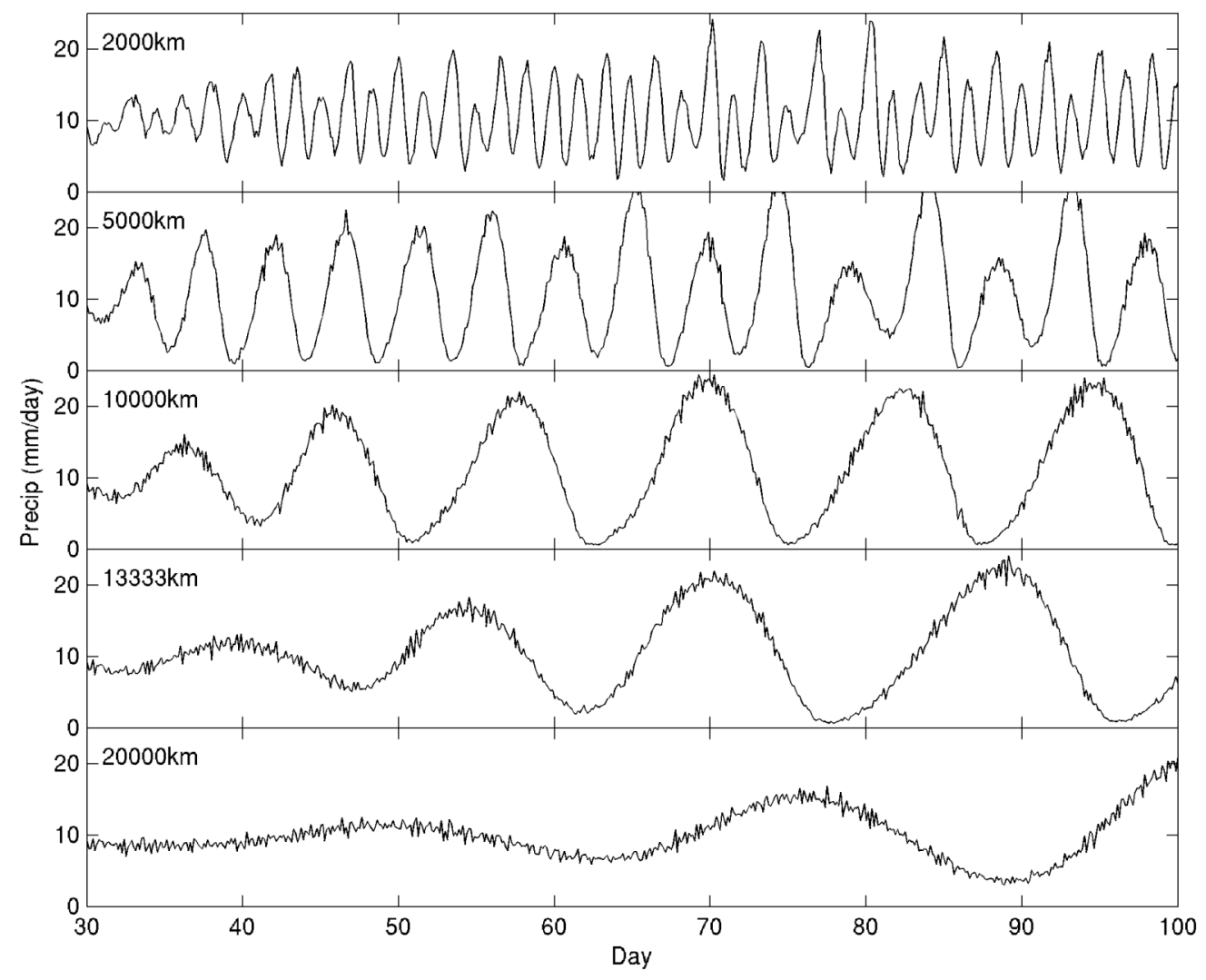

Figure 5 Same as Fig. 2 except for representative cases with no mechanical damping. 


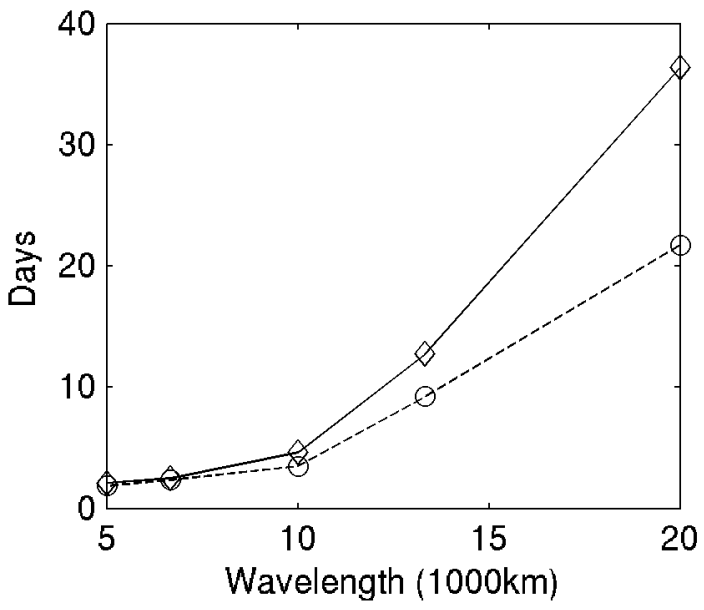

Figure 6 Time for the wave amplitude of the positive (dashed, circle) and negative (solid, diamond) phases to grow to $3 \mathrm{~mm} /$ day in the no mechanical damping cases. 


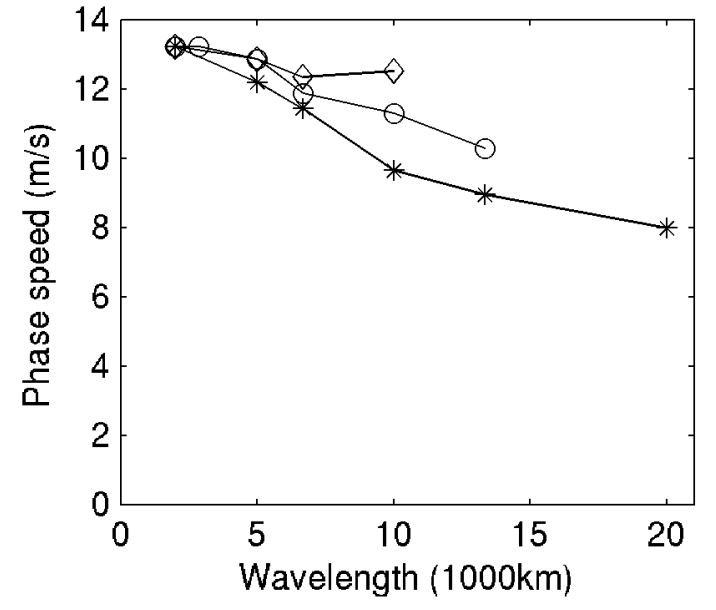

Figure 7 Estimated wave phase speeds at different wavelengths with a mechanical damping time of 4 days (diamonds), 10 days (circles), and with no mechanical damping (asterisks). 
(a)

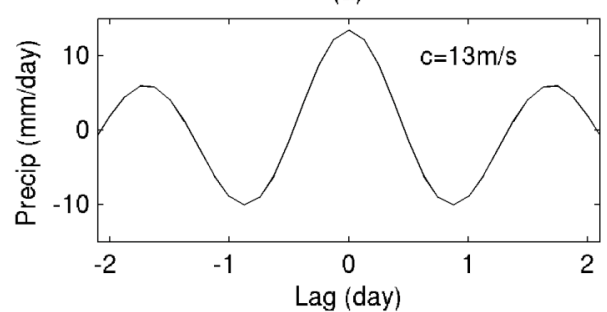

(c) q' $(0.1 \mathrm{~g} / \mathrm{kg})$

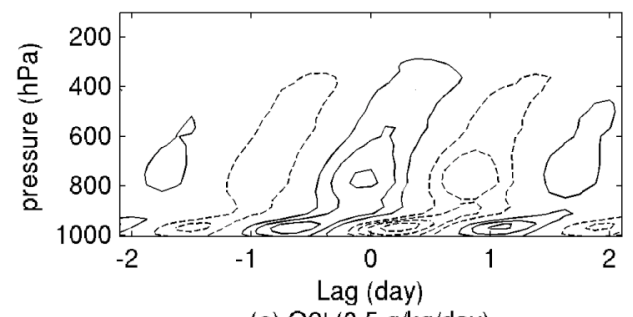

(e) Q2' (0.5 g/kg/day)

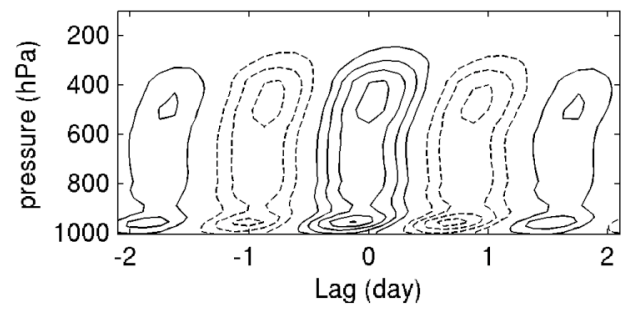

(b) $\mathrm{T}^{\prime}(0.1 \mathrm{C})$

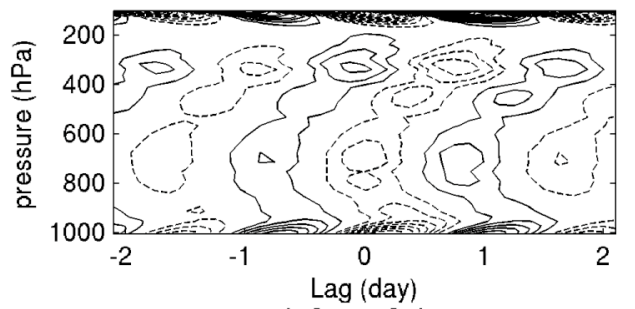

(d) Q1' (1 C/day)

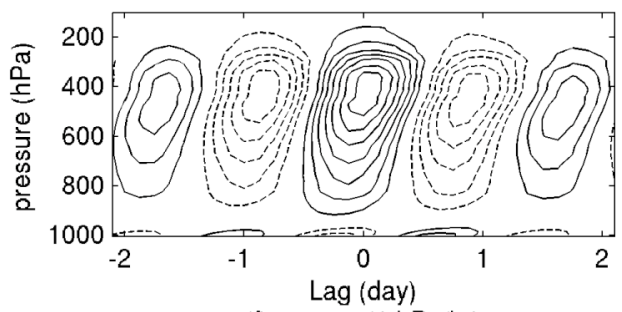

(f) omega' (1 hPa/hr)

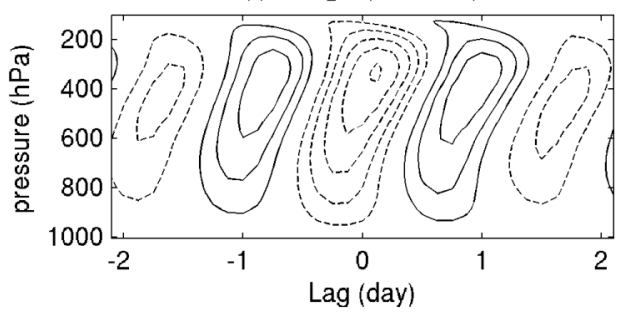

Figure 8 Composite wave structures for the wavelength of $2000 \mathrm{~km}$ : (a) precipitation, (b) temperature, (c) specific humidity, (d) convective heating, (e) convective drying, and (f) vertical pressure velocity. Contour intervals are indicated above each plot. Negative contours are dashed and the zero contours are omitted. The estimated phase speed is shown in (a). 
(a)

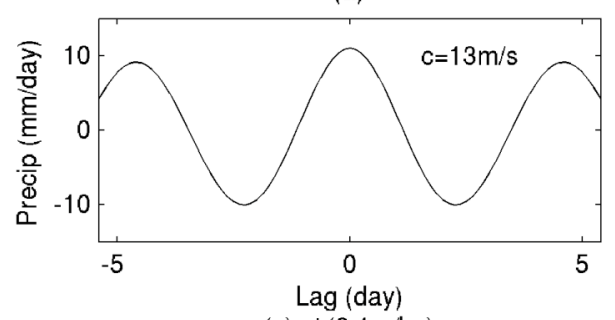

(c) q' $(0.1 \mathrm{~g} / \mathrm{kg})$

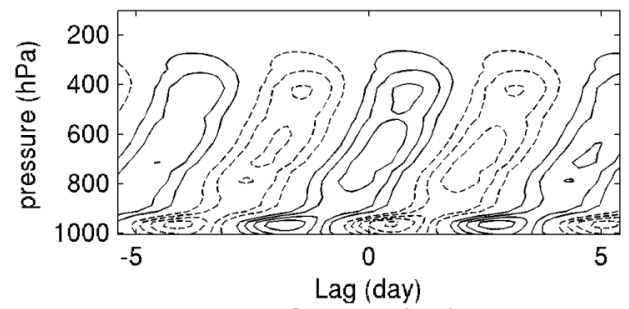

(e) Q2' $(0.5 \mathrm{~g} / \mathrm{kg} /$ day $)$

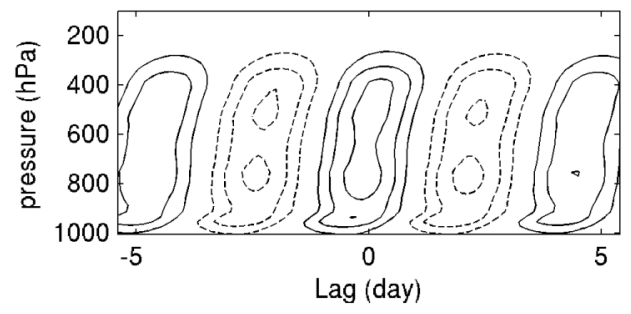

(b) $\mathrm{T}^{\prime}(0.1 \mathrm{C})$

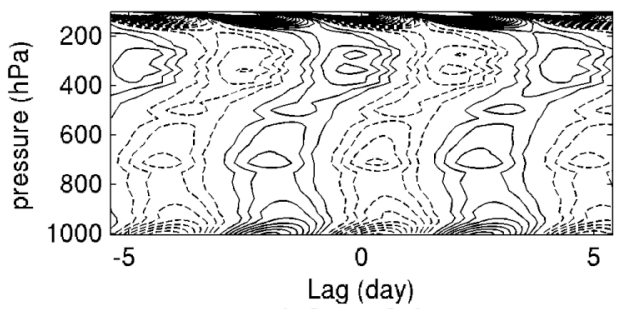

(d) Q1' (1 C/day)

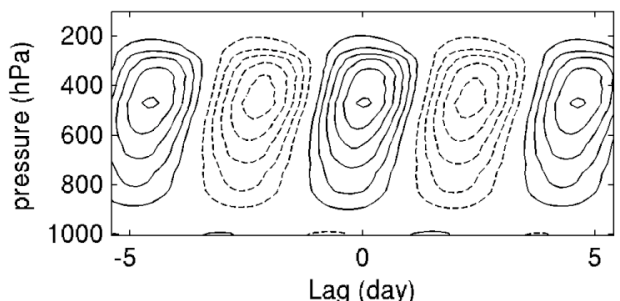

(f) omega' (1 hPa/hr)

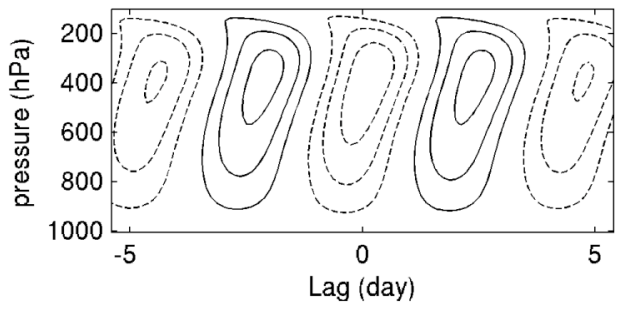

Figure 9 Same as Figure 8 but for the wavelength of $5000 \mathrm{~km}$. 
(a)

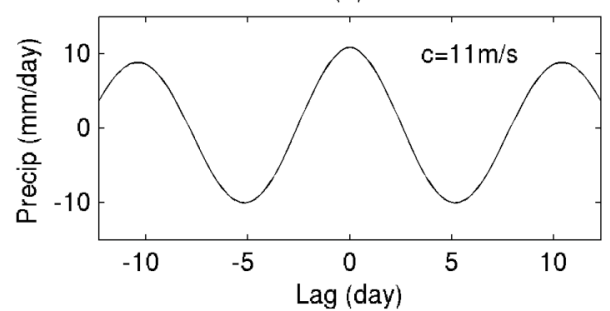

(c) q' $(0.1 \mathrm{~g} / \mathrm{kg})$

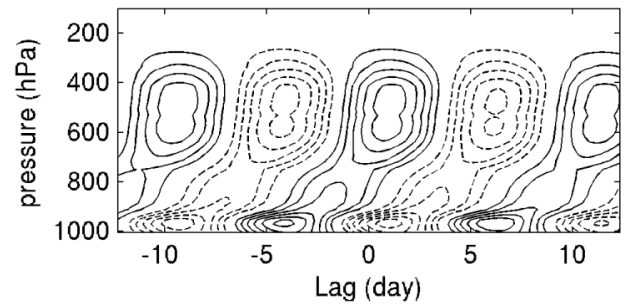

(e) Q2' (0.5 g/kg/day)

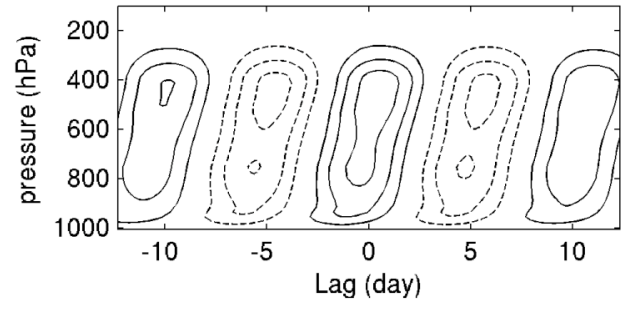

(b) $\mathrm{T}^{\prime}(0.1 \mathrm{C})$

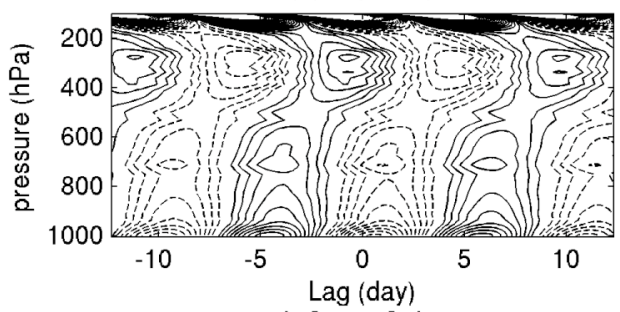

(d) Q1' (1 C/day)

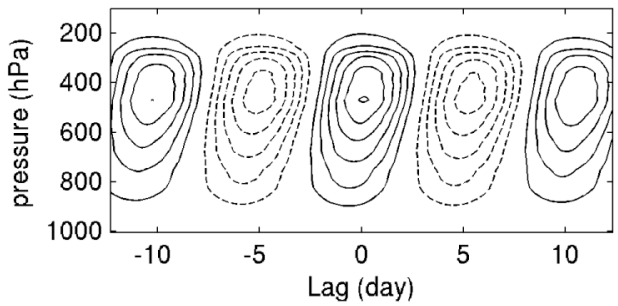

(f) omega' (1 hPa/hr)

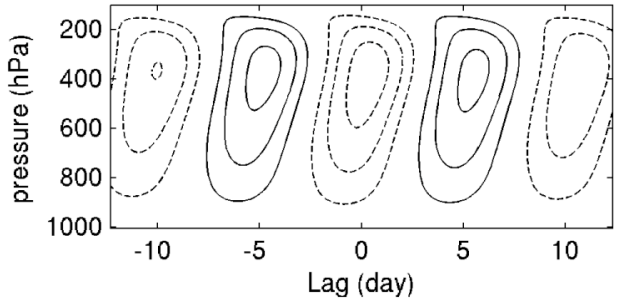

Figure 10 Same as Figure 8 but for the wavelength of $10000 \mathrm{~km}$. 
$T^{\prime}(0.1 \mathrm{C})$
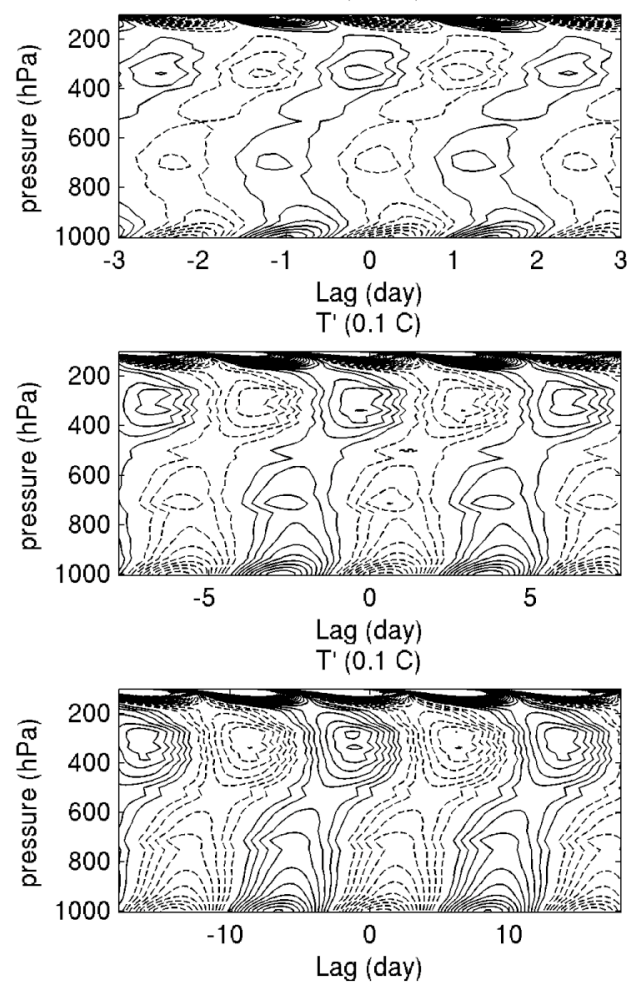

$\mathrm{q}^{\prime}(0.1 \mathrm{~g} / \mathrm{kg})$
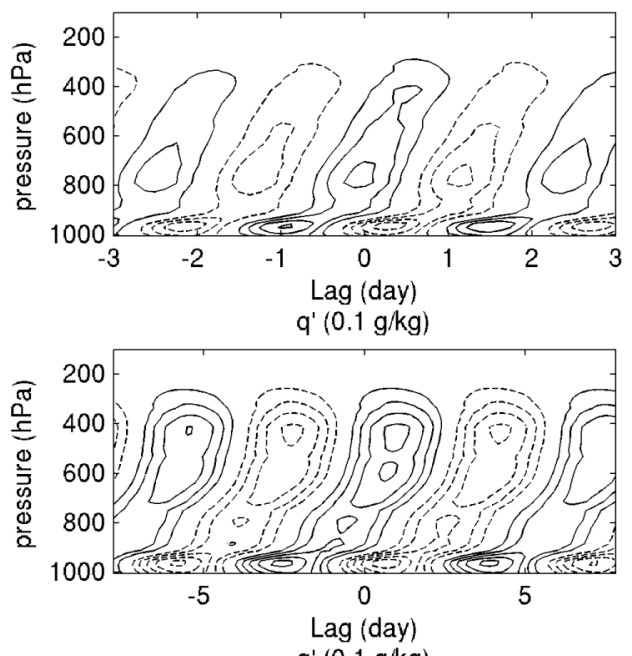

q' $(0.1 \mathrm{~g} / \mathrm{kg})$

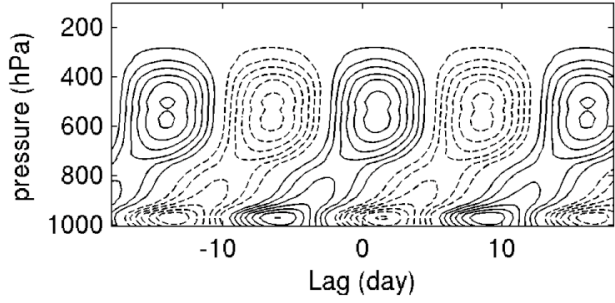

Figure 11 Same as Figure 8 except for temperature (left) and specific humidity (right) at wavelengths of (from top to bottom), $2857 \mathrm{~km}, 6667 \mathrm{~km}$, and $13333 \mathrm{~km}$. 
(a) $\mathrm{T}^{\prime}(0.1 \mathrm{C})$

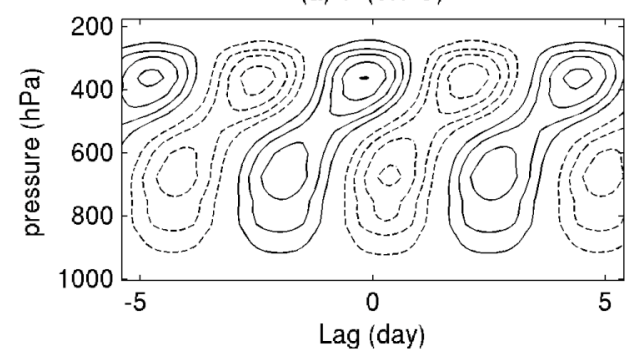

(b) Q1' (1 C/day)

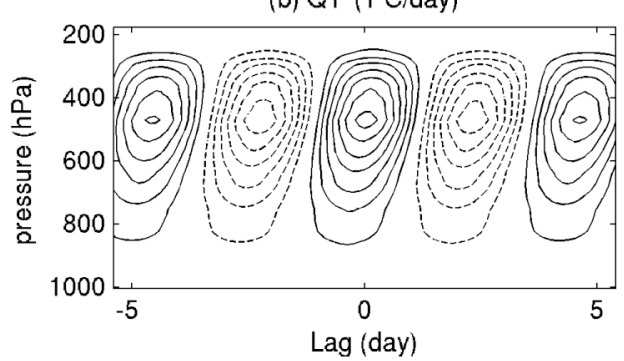

Figure 12 Temperature (left) and convective heating (right) structures reconstructed from the first two vertical modes. 
(a) $\mathrm{T}^{\prime}(0.1 \mathrm{C})$

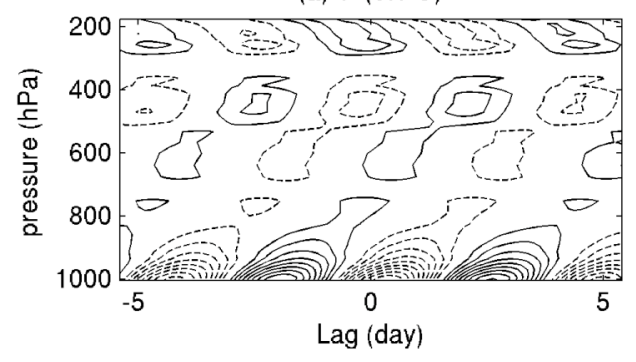

(b) Q1' (1 C/day)

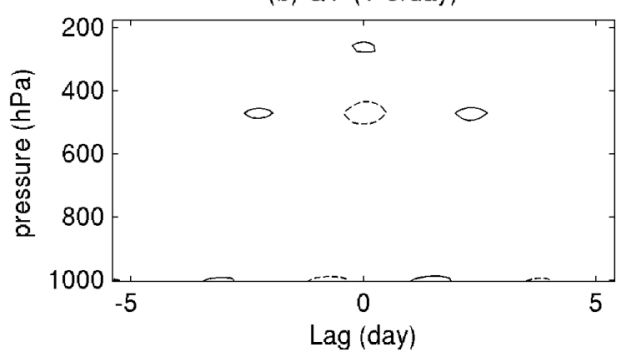

Figure 13 Residues in temperature (left) and convective heating (right) from reconstructing with the first two vertical modes. 


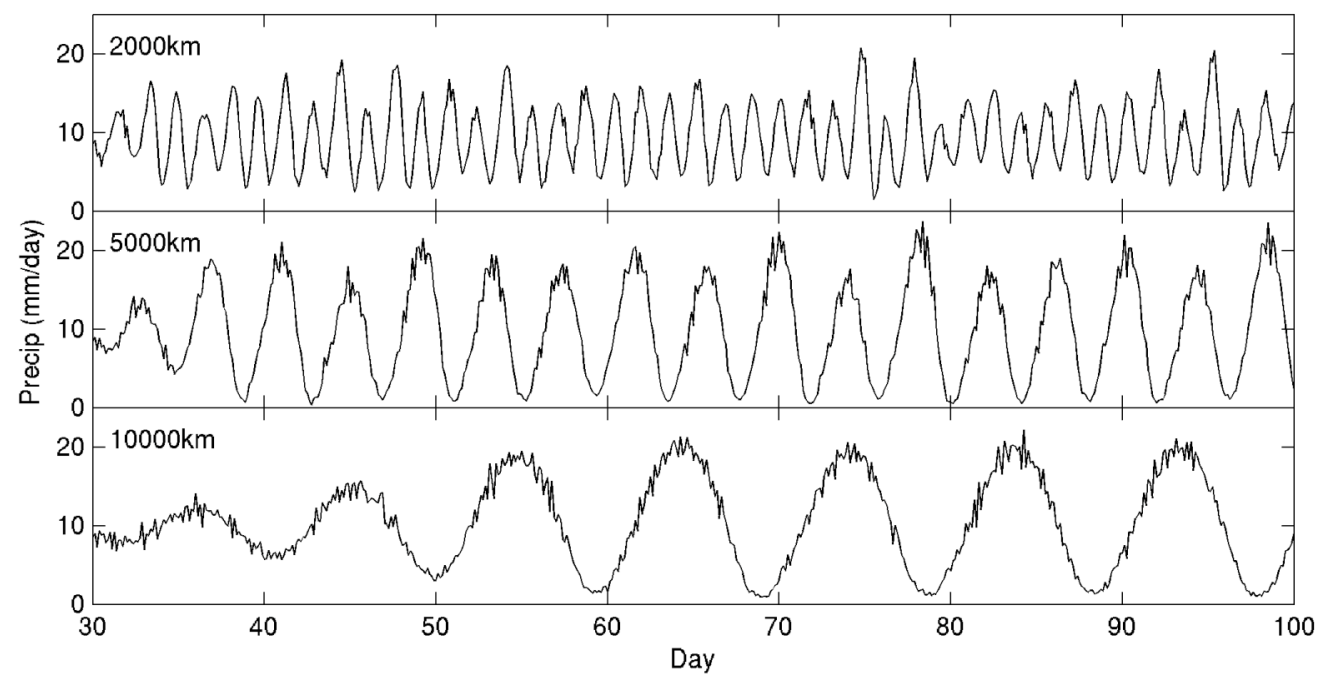

Figure 14 Same as Figure 2 except when a rigid lid condition is used at $14 \mathrm{~km}$ and for wavelengths of (from top to bottom) $2000 \mathrm{~km}, 5000 \mathrm{~km}$, and $10000 \mathrm{~km}$. 
(a)

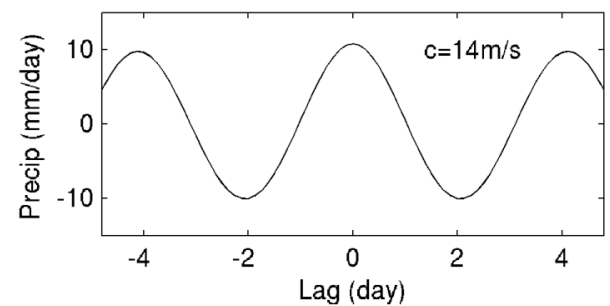

(c) q' $(0.1 \mathrm{~g} / \mathrm{kg})$

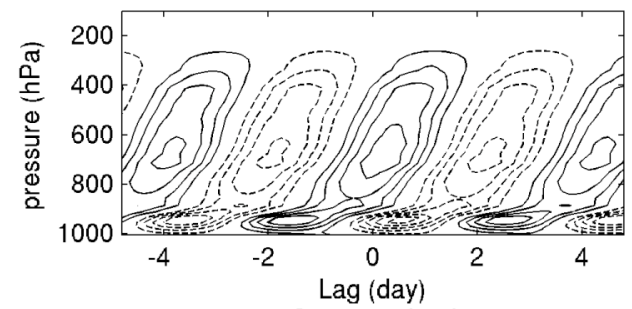

(e) Q2' (0.5 g/kg/day)

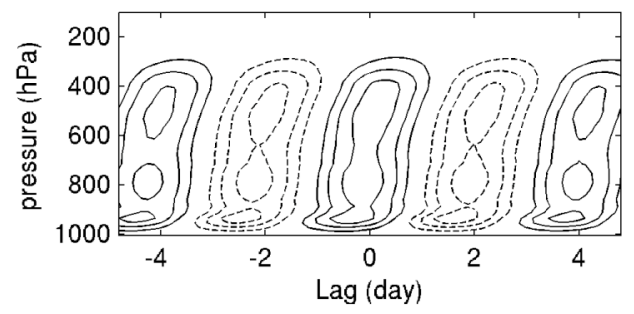

(b) $\mathrm{T}^{\prime}(0.1 \mathrm{C})$

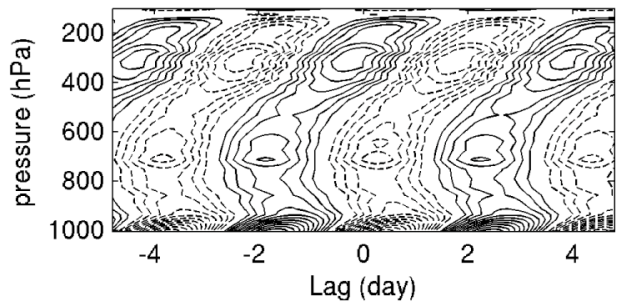

(d) Q1' (1 C/day)

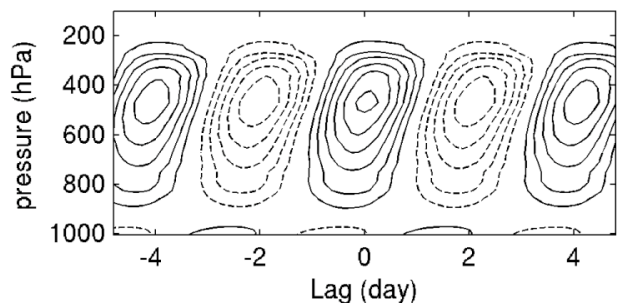

(f) omega' (1 hPa/hr)

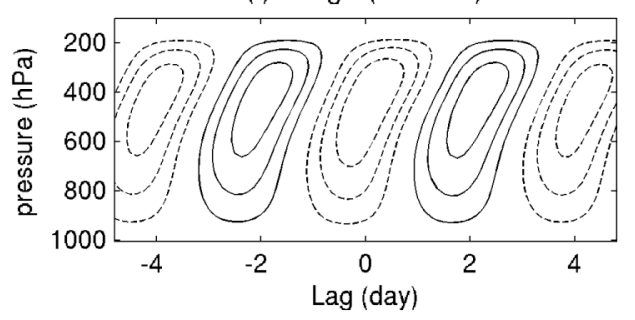

Figure 15 Same as Figure 9 except with a rigid lid at $14 \mathrm{~km}$ and constant surface heat fluxes. 


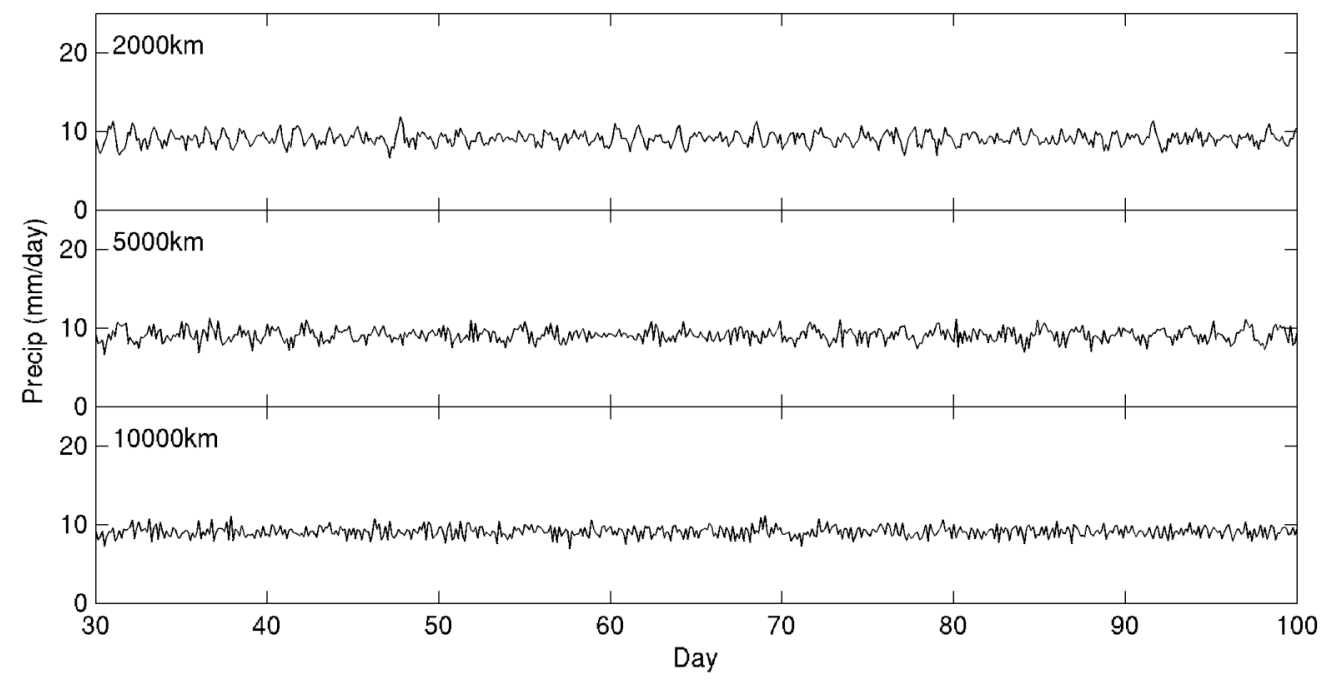

Figure 16 Same as Figure 2 except with vertical advection of moisture by large-scale waves disabled and for wavelengths of (from top to bottom) $2000 \mathrm{~km}, 5000 \mathrm{~km}$, and $10000 \mathrm{~km}$. 


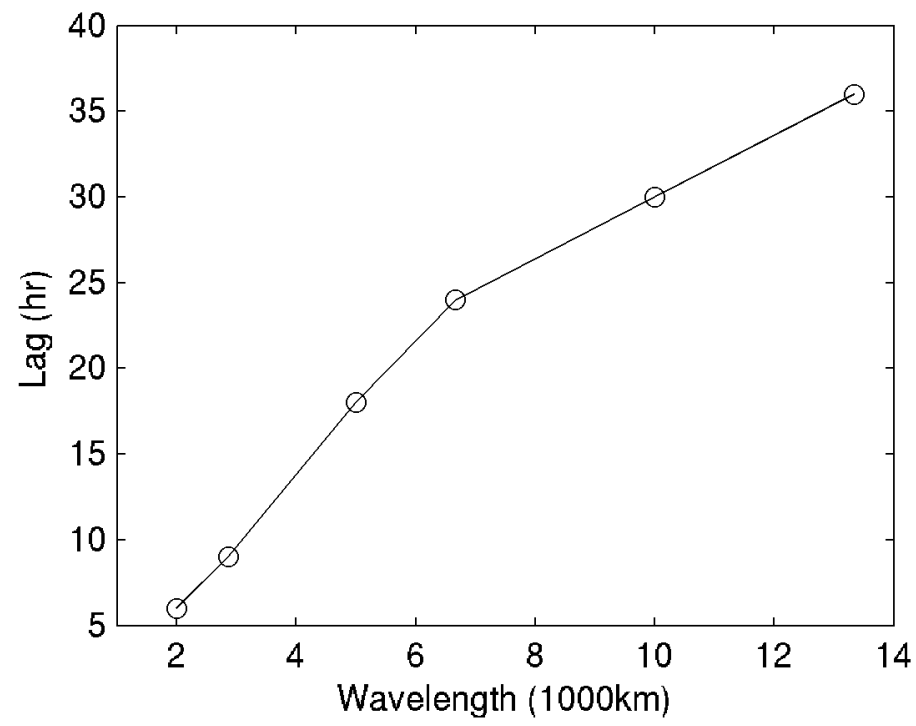

Figure 17 The estimated lag between deep convective heating and stratiform heating as a function of wavelength. 